\title{
Papers
}

\section{Interleukin-2 receptor monoclonal antibodies in renal transplantation: meta-analysis of randomised trials}

\author{
Dwomoa Adu, Paul Cockwell, Natalie J Ives, Jonathan Shaw, Keith Wheatley
}

\begin{abstract}
Objective To study the effect of interleukin-2 receptor monoclonal antibodies on acute rejection episodes, graft loss, deaths, and rate of infection and malignancy in patients with renal transplants. Design Meta-analysis of published data.

Data sources Medline, Embase, and Cochrane library for years 1996-2003 plus search of medical editors' trial amnesty and contact with manufacturers of the antibodies.

Selection of studies Randomised controlled trials comparing interleukin-2 receptor antibodies with placebo or no additional treatment in patients with renal transplants receiving ciclosporin based immunosuppression.

Results Eight randomised controlled trials involving 1871 patients met the selection criteria (although only 1858 patients were analysed). Interleukin-2 receptor antibodies significantly reduced the risk of acute rejection (odds ratio $0.51,95 \%$ confidence interval 0.42 to 0.63$)$. There were no significant differences in the rate of graft loss $(0.78,0.58$ to 1.04$)$, mortality $(0.75,0.46$ to 1.23$)$, overall incidence of infections $(0.97,0.77$ to 1.24$)$, incidence of cytomegalovirus infections $(0.81,0.62$ to 1.04$)$, or risk of malignancies at one year (0.82, 0.39 to 1.70$)$. The different antibodies had a similar sized effect on acute rejection (test for heterogeneity $\mathrm{P}=0.7)$ : anti-Tac $(0.37,0.16$ to $0.89)$, BT563 (0.37, 0.1 to 1.38$)$, basiliximab $(0.56,0.44$ to 0.72$)$, and daclizumab $(0.46,0.32$ to 0.67$)$. The reduction in acute rejections was similar for all ciclosporin based immunosuppression regimens (test for heterogeneity $\mathrm{P}=1.0$ ).

Conclusions Adding interleukin-2 receptor antibodies to ciclosporin based immunosuppression reduces episodes of acute rejection at six months by $49 \%$. There is no evidence of an increased risk of infective complications. Longer follow up studies are needed to confirm whether interleukin-2 receptor antibodies improve long term graft and patient survival.
\end{abstract}

\section{Introduction}

Over 15000 people in the United Kingdom have functioning renal transplants, almost half of all patients with end stage renal failure. ${ }^{1}$ Episodes of acute rejection reduce the chance of long term survival of the graft. ${ }^{23}$ However, increasing immunosuppression to lower the risk of acute rejection or to treat episodes of acute rejection increases the incidence of infections and malignancies. ${ }^{45}$

Acute rejection arises when alloreactive $\mathrm{T}$ cells infiltrate the graft. A critical step in the activation of these cells is the expression of the high affinity interleukin-2 receptor, which induces rapid proliferation of $\mathrm{T}$ cells when interleukin- 2 binds to it. ${ }^{6}$ The interleukin-2 receptor consists of three transmembrane protein chains: $\alpha$ (CD25), $\beta$ (CD122), and $\gamma$ (CD132). CD25 does not transduce a signal but associates with CD122 and CD132 to form the receptor that triggers signalling. ${ }^{7}$

Initial human studies with mouse monoclonal antibodies to CD25 showed a significant reduction in acute rejection, but patients developed anti-mouse antibodies. ${ }^{8}$ Chimeric and humanised antibodies to CD25 have been developed to overcome the problem of immunogenicity, but individual trials are not large enough to be clear about the effectiveness of these antibodies. We did a systematic review and quantitative meta-analysis of randomised trials of interleukin-2 receptor antibodies versus placebo in patients receiving ciclosporin based immunosuppression after renal transplantation.

\section{Methods}

\section{Literature search}

We searched Medline for studies published between 1966 and 2003 with the following search terms: basiliximab, daclizumab, Simulect, Zenapax, anti-Tac, LO-TACT-1, antibodies, monoclonal, receptors, interleukin-2, randomised controlled trial, clinical trial, double-blind, renal, and kidney transplantation. We used a similar search strategy in the Embase and Cochrane Library databases. To locate unpublished studies, we searched the medical editors' trial amnesty and contacted Novartis and Roche, the manufacturers of basiliximab and daclizumab. We also searched the reference lists of identified papers and previous reviews for relevant studies.

\section{Selection of trials}

Studies had to meet the following criteria: treatment assigned by randomisation; all patients received standard immunosuppression; the experimental group received interleukin- 2 receptor antibody; the control
Department of Nephrology, Queen Elizabeth Hospital, Birmingham, B15 2TH

Dwomoa Adu consultant nephrologist Paul Cockwell consultant nephrologist Jonathan Shaw house physician

Birmingham Clinical Trials Unit, Park Grange, Birmingham B15 2RR

Natalie J Ives statistician Keith Wheatley professor

Correspondence to: D Adu dwomoa.adu@ uhb.nhs.uk

bmj.com 2003;326:789 


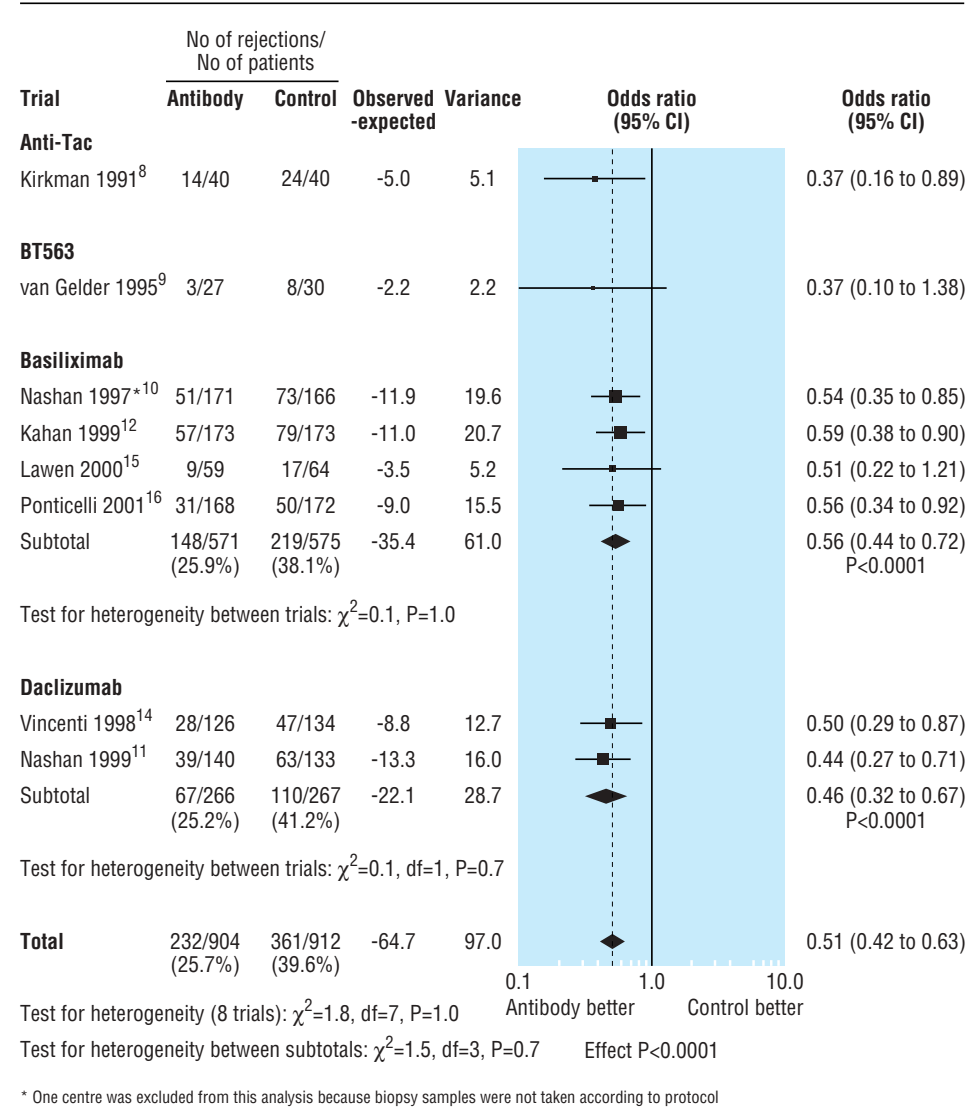

Fig 1 Incidence of acute rejection by type of interleukin-2 receptor antibody. Note that only overall follow up data (six to 26 months) were available for anti-Tac and 12 week data for BT563

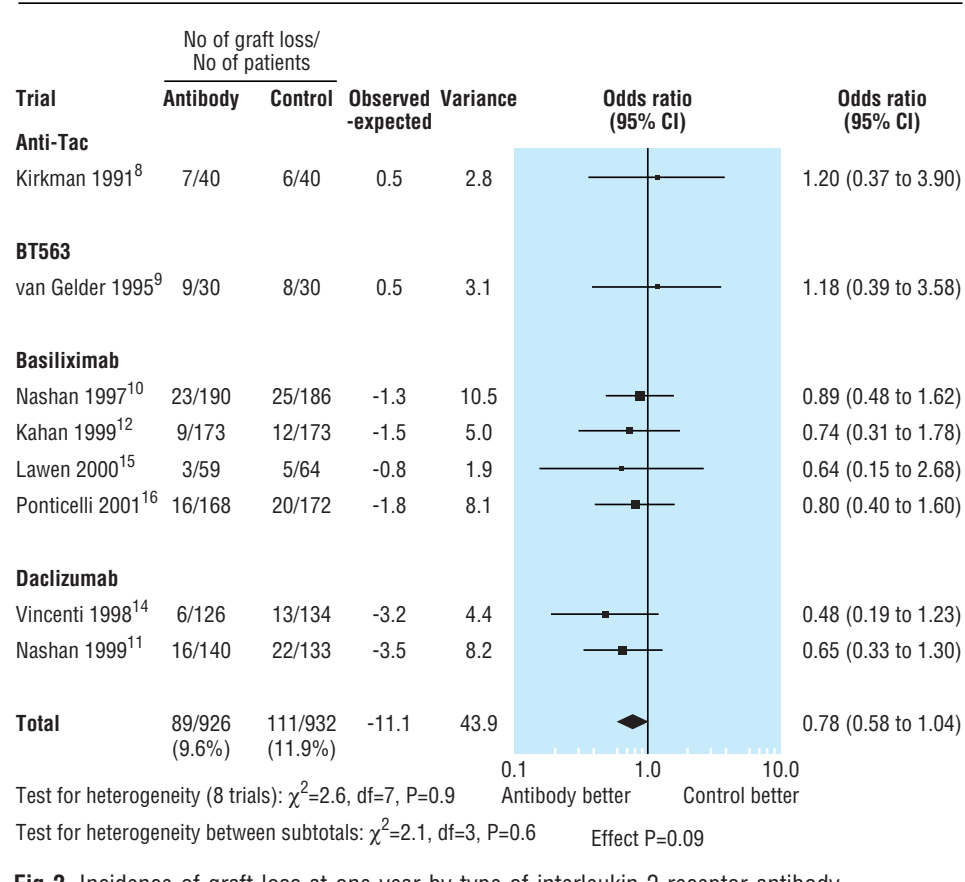

Fig 2 Incidence of graft loss at one year by type of interleukin-2 receptor antibody

group received placebo or no other drug. Three investigators (JS, DA, and NJI) examined each eligible study and recorded method of randomisation, treatment in both arms of the study, and outcome measures. They also recorded details of actual treatment and its duration.

Outcome measures and statistics

The main outcome measures were biopsy proved acute rejection at six months after transplantation, graft loss and death at 12 months, and incidence of infections, cytomegalovirus infections, and malignancy at 3, 6, or 12 months.

One study excluded data on 20 control patients and 19 patients treated with basiliximab from the analysis of acute rejection because biopsy samples were not taken according to the protocol. ${ }^{10}$ Four studies excluded data from a total of 11 patients who did not receive a transplant ${ }^{10-12}$ or lost their grafts because of technical reasons or renal artery thrombosis. ${ }^{9}$

We determined the number of patients with each outcome measure in the antibody and control groups for each trial from the published papers. We then used standard methods for overviews based on published data. ${ }^{13}$ To summarise, for each trial we calculated the expected number of events in the interleukin-2 group and then the difference between the observed and expected numbers and its variance. The sum of the statistics for each trial provided the overall statistics, which we used to calculate odd ratios with $95 \%$ confidence intervals. All $\mathrm{P}$ values are two tailed.

\section{Results}

Eight trials fulfilled the inclusion criteria. ${ }^{8-12}{ }^{14-16}$ The table summarises the baseline characteristics of patients in these studies. Four studies used cadaveric donors only, ${ }^{8} 10^{11} 14$ and four studies included both cadaveric and living donors. ${ }^{9} 121516$ Two of the studies included patients receiving second transplants. ${ }^{1516}$ All but one of the studies ${ }^{8}$ used a double blind method of randomisation. Four studies described the method of randomisation in detail, of which one used sealed envelopes, ${ }^{8}$ two used 1:1 randomisation, ${ }^{12}{ }^{16}$ and one assigned randomly in a 1:1 ratio using an automated randomisation program at each centre and held the results in a set of sealed envelopes. ${ }^{10}$ In one study, the patients in the control arm did not receive placebo. ${ }^{8}$

The baseline immunosuppression varied between studies. Four studies used ciclosporin and prednisolone, ${ }^{9-12}$ three studies used ciclosporin, azathioprine, and prednisolone, ${ }^{814}$ and one study used ciclosporin, mycophenolate mofetil, and prednisolone. ${ }^{15}$ Two studies gave both ciclosporin dose and target concentrations, ${ }^{9}{ }^{16}$ two studies defined target ciclosporin concentrations, ${ }^{10} 11$ and three studies gave the dose of ciclosporin. ${ }^{81115}$ All but one study, which used ciclosporin, azathioprine, and steroids, ${ }^{14}$ gave doses of the other immunosuppressants used.

The overall proportion of patients with acute rejection at six months was 361/912 (39.6\%) in the control group compared with 232/904 (25.7\%) in the antibody group (fig 1). Treatment with interleukin-2 receptor antibodies was associated with a significant reduction in the risk of acute rejection at six months (odds ratio $0.51 ; 95 \%$ confidence interval 0.42 to $0.63 ; \mathrm{P}<0.0001$ ) Figures 2 and 3 show that patients treated with antibodies had no significant reductions in graft loss at one year $(0.78,0.58$ to $1.04 ; \mathrm{P}=0.09)$ or in mortality at one year $(0.75,0.46$ to $1.23 ; \mathrm{P}=0.3)$. 
The proportion of patients with infections and cytomegalovirus infection was reported at three months in one trial, ${ }^{9}$ at six months in four trials, ${ }^{114-16}$ and at 12 months in three trials. ${ }^{8}{ }^{10}{ }^{12}$ However in three trials the data were not given in a form that was evaluable. $^{89}{ }^{14}$ Treatment with interleukin-2 receptor antibodies had no significant effect on overall infection (0.97, 0.77 to $1.24 ; \mathrm{P}=0.8$; fig 4 ) or cytomegalovirus infection ( $0.81,0.62$ to $1.04 ; \mathrm{P}=0.1$; fig 5 ). Fig 6 shows there was no difference in the risk of lymphoma or other malignancies at one year $(0.82,0.39$ to 1.70 ; $\mathrm{P}=0.6)$.

The effect on acute rejection was similar for all types of interleukin-2 receptor antibody (fig 1): anti-Tac (0.37, 0.16 to $0.89 ; \mathrm{P}=0.03$ ), BT563 (0.37, 0.1 to 1.38 ; $\mathrm{P}=0.1)$, basiliximab $(0.56,0.44$ to $0.72 ; \mathrm{P}<0.0001)$, and daclizumab $(0.46,0.32$ to $0.67 ; \mathrm{P}<0.0001)$. The test for heterogeneity between antibody groups was not significant $(\mathrm{P}=0.7)$.

The reduction in acute rejection was similar for all baseline immunosuppression regimens (fig 7). The odds ratio was $0.52(95 \%$ confidence interval 0.40 to $0.67 ; \mathrm{P}<0.0001)$ for patients treated with ciclosporin and prednisolone; 0.5 (0.36 to $0.71 ; \mathrm{P}<0.0001)$ with ciclosporin, prednisolone, and azathioprine; and 0.51 (0.22 to $1.21 ; \mathrm{P}=0.1)$ with ciclosporin, prednisolone, and mycophenolate mofetil. There was no evidence of heterogeneity between the three immunosuppression treatment groups $(\mathrm{P}=1.0)$ or between the trials for any of the other outcomes.

\section{Discussion}

This meta-analysis confirms that adding interleukin-2 receptor antibodies to standard ciclosporin based immunosuppression greatly reduces the risk of rejection. Acute rejection proved by biopsy was reduced by $49 \%$ at six months. We also found non-significant reductions in graft loss and mortality, and there was no evidence of increased incidence of infections or risk of malignancy. The size of the reduction in acute rejections was similar for the different antibodies and immunosuppression regimens.

Reducing the rate of acute rejection is important in renal transplantation, as patients who have had one or more episodes of acute rejection have at least a $50 \%$ reduction in long term graft survival. ${ }^{2}$ Because one

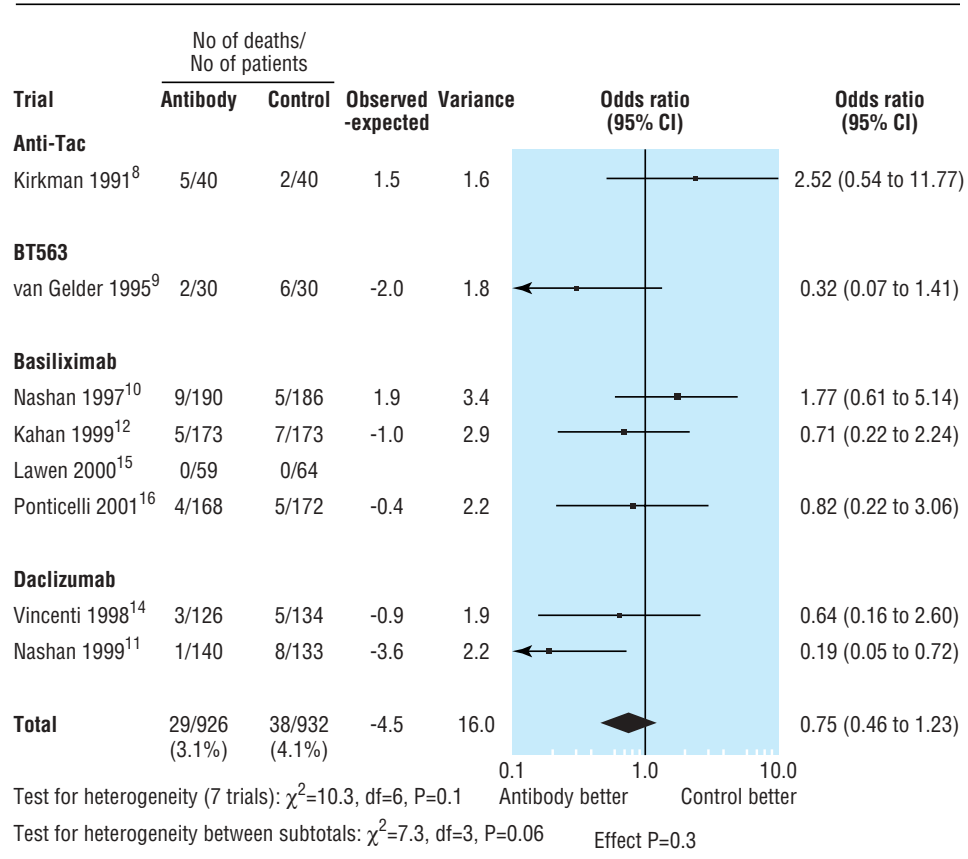

Fig 3 Number of deaths at one year by type of interleukin-2 receptor antibody

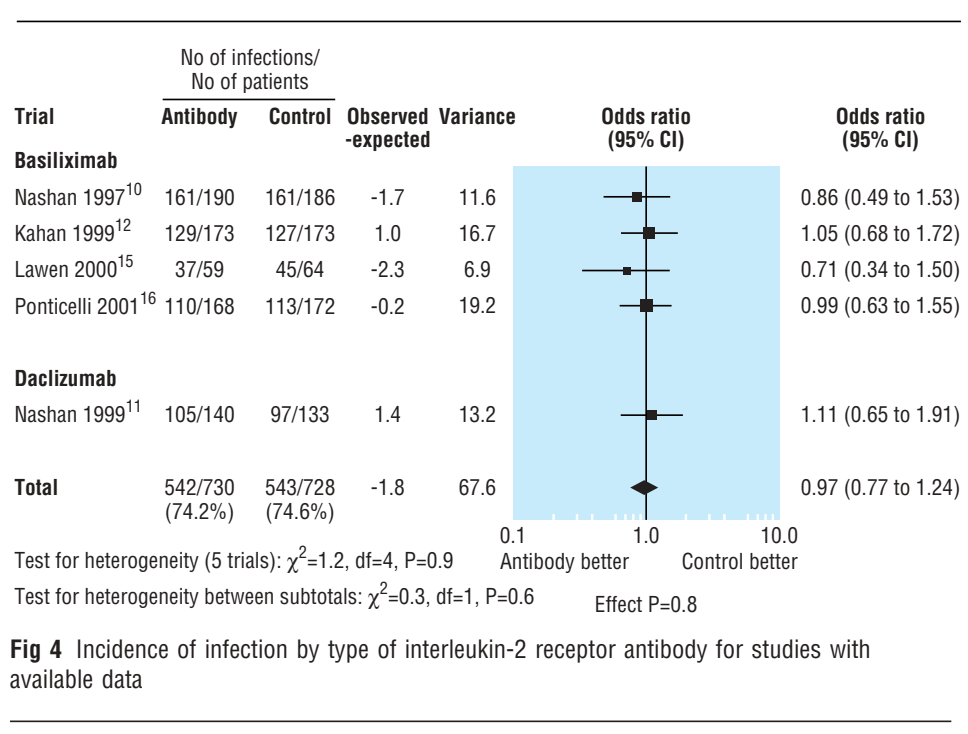

Monoclonal antibody and baseline characteristics of patients in studies included in analysis. Patient values are for interleukin receptor antibody group/control group (placebo or no additional treatment)

\begin{tabular}{|c|c|c|c|c|c|c|c|c|}
\hline Characteristic & Kirkman $1991^{8}$ & $\begin{array}{c}\text { van Gelder } \\
1995^{\circ}\end{array}$ & $\begin{array}{l}\text { Nashan } \\
1997^{10}\end{array}$ & $\begin{array}{l}\text { Vincenti } \\
1998^{14}\end{array}$ & Nashan $1999^{11}$ & Kahan $1999^{12}$ & Lawen $2003^{15}$ & $\begin{array}{l}\text { Ponticelli } \\
2001^{16}\end{array}$ \\
\hline Monoclonal antibody & MurinelgG2a & MurinelgG1 & Basiliximab & Daclizumab & Daclizumab & Basiliximab & Basiliximab & Basiliximab \\
\hline No of patients & $40 / 40$ & $30 / 30$ & 193/187 & $126 / 134$ & $140 / 133$ & $173 / 173$ & $59 / 64$ & 168/172 \\
\hline Mean age (years) & $44 / 44$ & $43 / 45^{\star}$ & $49 / 48^{\star}$ & $47 / 47$ & $44 / 46$ & $45 / 46$ & $45 / 46$ & $44 / 44$ \\
\hline$\%$ men & $58 / 65$ & $60 / 63$ & $66 / 63$ & $59 / 60$ & $74 / 67$ & $64 / 62$ & $76 / 64$ & $66 / 69$ \\
\hline$\%$ having first transplant & $100 / 100$ & $100 / 100$ & $100 / 100$ & $100 / 100$ & $100 / 100$ & $100 / 100$ & $90 / 88$ & $93 / 94$ \\
\hline \multicolumn{9}{|l|}{ Diagnosis (\%): } \\
\hline Glomerulonephritis & $45 / 35$ & NA & $32 / 40$ & $26 / 30$ & $43 / 41$ & NA & $30 / 29$ & NA \\
\hline Hereditary & $28 / 25$ & NA & $17 / 17$ & $19 / 15$ & $15 / 14$ & NA & $10 / 15$ & NA \\
\hline $\begin{array}{l}\text { Pyelonephritis/ } \\
\text { interstitial nephritis }\end{array}$ & NA† & NA & $10 / 10$ & NA & $13 / 11$ & NA & $10 / 6$ & NA \\
\hline Diabetes & $0 / 5$ & NA & $7 / 5$ & $25 / 22$ & $3 / 8$ & NA & $10 / 6$ & NA \\
\hline Other or unknown & $25 / 30$ & NA & $35 / 28$ & $29 / 33$ & $26 / 26$ & NA & $40 / 43$ & NA \\
\hline
\end{tabular}

$\mathrm{NA}=$ not available.

*Ages given as median.

†Pyelonephritis numbers not stated. One patient in each group had interstitial nephritis. 


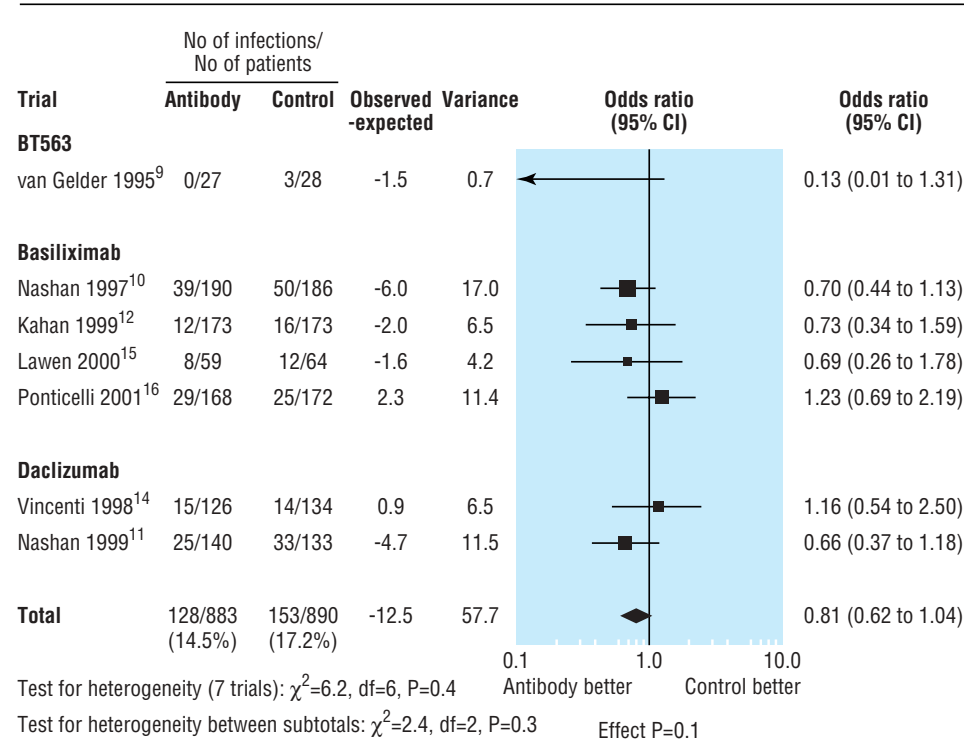

Fig 5 Incidence of cytomegalovirus infection by type of interleukin-2 receptor antibody for studies with available data

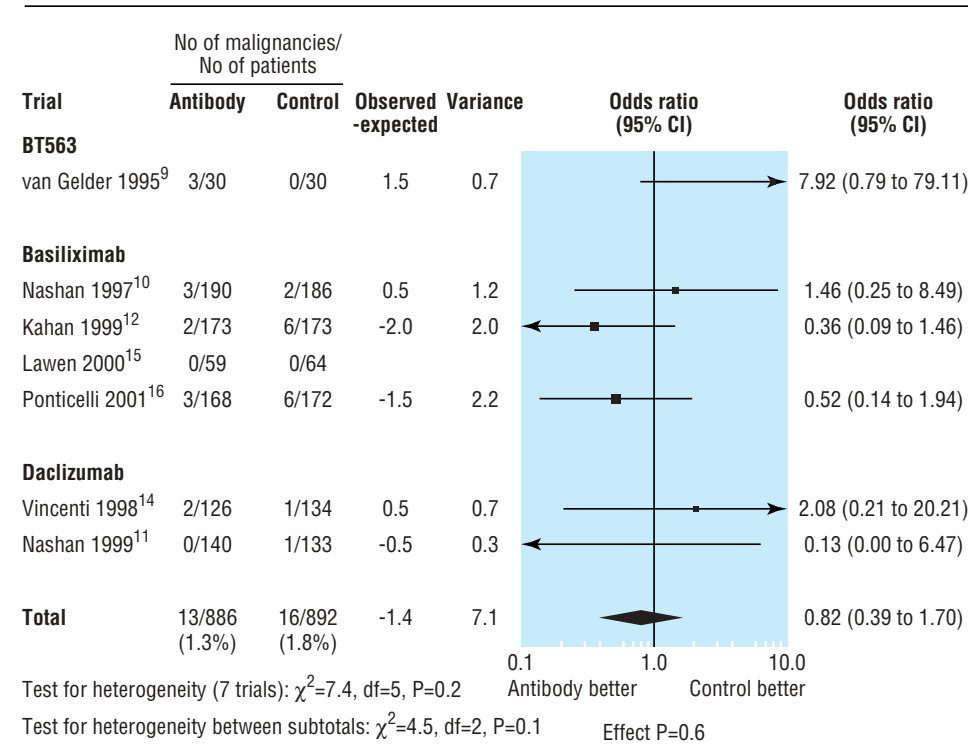

Fig 6 Incidence of lymphoma and malignancies at one year by type of interleukin-2 receptor antibody for studies with available data

year graft survival for renal transplantation is about $90 \%,{ }^{2}$ studies with follow up for more than one year are needed to determine the long term effect on graft loss.

A major concern with the addition of immunosuppression to standard regimens is the increased incidence of side effects. Although we found no increase in the incidence of malignancies in patients treated with interleukin-2 receptor antibodies compared with the control group at one year, the follow up was too short to draw useful conclusions. We found no evidence of an increase in the risk of infections. This is important because analyses of treatment with antilymphocyte antibodies in renal allograft recipients have shown an increased risk of infection. ${ }^{45}$ Finally, we found some evidence of a reduction in the incidence of cytomegalovirus infections in patients treated with antibodies compared with the control group.
Some centres in the United Kingdom use tacrolimus based immunosuppression. A meta-analysis showed that this regimen reduced the risk of acute rejection but not graft loss compared with ciclosporin based immunosuppression. ${ }^{17}$ There are no randomised controlled studies of interleukin-2 receptor antibodies in patients with renal transplants treated with tacrolimus based immunosuppression.

\section{Validity of results}

Meta-analysis based on published data has some limitations. The published results were presented as intention to treat, suggesting that all randomised patients were included in the analysis. However, one study excluded data from one centre as it did not collect biopsy samples according to the protocol. ${ }^{10}$ Furthermore, three studies defined the intention to treat analysis as including only patients who actually had renal transplantation. ${ }^{10-12}$ Two patients (one patient from each arm) in two of the studies, ${ }^{11}{ }^{12}$ and four (three from the interleukin-2 group and one from the placebo group) in the other study ${ }^{10}$ were therefore excluded from analysis because they never had a renal transplant. Another study excluded three patients from the analysis because they lost their graft because of technical reasons or renal artery thrombosis. ${ }^{9}$ These exclusions mean that the results are not strictly intention to treat, but the number of patients excluded is small (11 in total) and therefore unlikely to bias the results.

As with all meta-analyses of published data, there is the potential problem of publication bias. We did a comprehensive literature search to identify published data and approached the medical editors' trial amnesty and antibody manufacturers to try to identify unpublished studies. It therefore seems unlikely that this would be a substantial source of bias. Ideally, metaanalysis should be done on individual patient data, but this is time consuming and labour intensive.

\section{Conclusions}

Our results show that interleukin-2 receptor antibodies reduce the risk of episodes of acute rejection in patients with renal transplants. This reduction was not accompanied by an increased risk of infection. Longer term studies are now needed to determine the effect on long term survival of the grafts and the effect on risk of malignancy.

Contributors: All authors contributed to the design, analysis, and interpretation of the study. DA will act as guarantor. Funding: No funding was sought for this study

Competing interests: DA is an investigator in a trial of fluvastatin in renal transplant recipients that is funded by Novartis; PC and DA have a grant from Roche to study chronic allograft nephropathy; PC has an unrestricted educational grant from Novartis to support research into early immune events after renal transplantation, has received support from Roche and Novartis to attend transplant meetings, and has spoken at educational meetings sponsored by these companies.

1 UK Transplant website. www.uktransplant.org (accessed 25 February 2003).

2 Hariharan S, Johnson C, Bresnahan B, Taranto S, McIntosh M, Stablein D. Improved graft survival after renal transplantation in the United States, 1988 to 1996. N Engl J Med 2000;342:605-12.

3 Matas A, Gillingham K, Payne W, Najarian J. The impact of an acute rejection episode on long-term renal allograft survival. Transplantation 1994:57:857-9.

4 Kamel O, van de Rijn M, Lebrun D, Weiss L, Warnke R, Dorfman R. A multivariate analysis of discharge immunosuppression and posttransplant malignancy. Am J Transplant 2001;1(suppl 1):353. 


\section{What is already known on this topic}

Episodes of acute rejection reduce graft survival in patients with renal transplants

Increasing immunosuppression to reduce rejection can increase infection and malignancy

\section{What this study adds}

Addition of interleukin-2 receptor antibodies to ciclosporin based immunosuppression regimens halves the risk of acute rejection

Patients receiving antibodies did not have an increased risk of infection

The effects on graft loss and mortality at one year were not significant

5 Jamil B, Nicholls K, Becker G, Walker R. Impact of acute rejection therapy on infections and malignancies in renal transplant recipients. Transplan tation 1999;68:1597-619

6 Morgan D, Ruscettis F, Gallo R. Selective in vitro growth of T lymphocytes from normal human bone marrow. Science 1976;193:1007-8.

7 Robb R, Greene W, Rusk C. Low and high affinity cellular receptors for interleukin 2: implications for the level of Tac antigen. $J$ Exp Med 1984;162:358-62.

8 Kirkman R, Shapiro ME, Carpenter CB, McKay DB, Milford EL, Ramos $\mathrm{EL}$, et al. A randomised trial of anti-Tac monoclonal antibody in human renal transplantation. Transplantation 1991:51:107-13.

9 Van Gelder T, Zietse R, Mulder AH, Yzermans JNM, Hesse CJ, Vaessen LMB, et al. A double blind, placebo-controlled study of monoclonal antiinterleukin-2 receptor antibody (BT563) administration to prevent acute rejection after kidney transplantation. Transplantation 1995;60:248-52.

10 Nashan B, Moore R, Schmidt A-G, Abeywickrama K, Soulillou J-P. Randomised trial of basiliximab versus placebo for control of acute cellular rejection in renal allograft recipients. Lancet 1997;350:1193-8.

11 Nashan B, Light S, Hardie I, Lin A, Johnson J. Reduction of acute renal allograft rejection by daclizumab: Daclizumab Double Therapy Study Group. Transplantation 1999;67:110-5.

12 Kahan B, Rajagopalan P, Hall M. Reduction of the occurrence of acute cellular rejection among renal allograft recipients treated with basiliximab, a chimeric anti-interleukin-2 receptor monoclonal antibody. Transplantation 1999;67:276-84

13 Early Breast Cancer Treatment Collaborative Group. Treatment of early breast cancer: worldwide evidence 1985-1990. Oxford: Oxford University Press, 1990

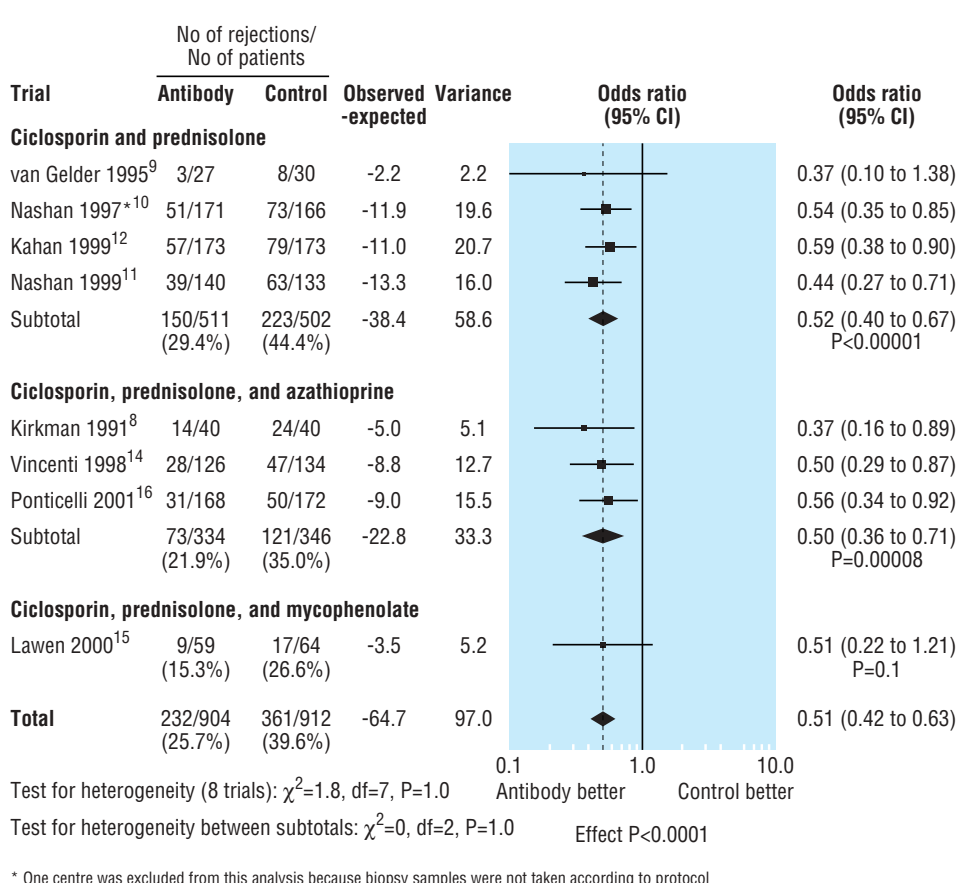

Fig 7 Incidence of acute rejection at six months by immunosuppression regimen

14 Vincenti F, Kirkman R, Light S, Bumgardner G, Pescovitz M, Halloran P, et al. Interleukin-2-receptor blockade with daclizumab to prevent acute rejection in renal transplantation. N Engl J Med 1998:338:161-5.

15 Lawen JG, Davies EA, Mourad G, Oppenheimer F, Molina MG, Rostaing L, et al. Randomized double-blind study of immunoprophylaxis with basiliximab, a chimeric anti-interleukin-2 receptor monoclonal antibody, in combination with mycophenolate mofetil-containing triple therapy in renal transplantation. Transplantation 2003;75:37-43.

16 Ponticelli C, Yussim A, Cambi V, Legendre C, Rizzo G, Salvadori M, et al. A randomised double-blind trial of basiliximab immunoprophylaxis plus triple therapy in kidney transplant recipients. Transplantation 2001;72:1261-7.

17 Knoll G, Bell R. Tacrolimus versus cyclosporin for immunosuppression in renal transplantation: meta-analysis of randomised trials. BMJ 1999;318:1104-7.

(Accepted 14 February 2003) 